\title{
Melatonin inhibits the endoplasmic reticulum stress-induced, C/EBP homologous protein-mediated pathway in acute pancreatitis
}

\author{
QIAN ZHAO $^{1 *}$, HUI ZHANG ${ }^{2 *}$, JIE WU $^{1}$, XIANGYIN LV ${ }^{1}$, XIANGHONG JIN ${ }^{1}$ and JIANWEN HU ${ }^{1}$ \\ ${ }^{1}$ Department of Gastroenterology, Dongyang People's Hospital; ${ }^{2}$ Department of Gastroenterology, \\ Weishan Branch of Dongyang People's Hospital, Dongyang, Zhejiang 322100, P.R. China
}

Received July 4, 2019; Accepted April 9, 2020

DOI: $10.3892 / \mathrm{mmr} .2020 .11219$

\begin{abstract}
Melatonin, which is mainly secreted by the pineal gland, appears to have anti-inflammatory activities. Acute pancreatitis (AP) is characterized by inflammation and acinar cell death, and is associated with a high mortality rate. It has been reported that melatonin can alleviate cerulein (Cer) or Cer + lipopolysaccharide (LPS)-induced inflammatory responses in AR42J rat pancreatic acinar cells (AR42J cells). CCAAT/enhancer binding protein homologous protein (CHOP) is a specific transcription factor involved in endoplasmic reticulum (ER) stress-induced apoptosis, and regulates ER stress responses. However, the mechanisms of the anti-inflammatory effects of melatonin' are unknown, particularly the relationship between melatonin and ER stress. Therefore, the present study aimed to investigate the anti-inflammatory activity of melatonin in AR42J cells and analyze its molecular mechanisms during ER stress. The RNA interference method was used to determine the potential role of CHOP in AR42J cells during AP. In vitro models of AP were induced by treating AR42J cells with Cer + LPS, and pre-treatment with melatonin was used to identify the potential anti-inflammatory mechanisms. The cells also underwent Cell Counting Kit-8, western blotting and reverse transcription-quantitative PCR analyses. The expression levels of ER stress-related molecules were rapidly activated in the early stage and increased over time in the AR42J AP models, with significant pancreatic inflammation and apoptosis. However, knockdown of CHOP expression significantly reduced apoptosis, the activation of $\mathrm{NF}-\kappa \mathrm{B}$ and the downstream signal pathway. Moreover, cells
\end{abstract}

Correspondence to: Professor Jianwen $\mathrm{Hu}$, Department of Gastroenterology, Dongyang People's Hospital, 60 Wuning West Road, Dongyang, Zhejiang 322100, P.R. China

E-mail: 18367908196@163.com

*Contributed equally

Key words: melatonin, endoplasmic reticulum stress, CCAAT/enhancer binding protein homologous protein, acute pancreatitis, apoptosis, inflammation treated with melatonin exhibited attenuated inflammation, decreased expression levels of ER stress-associated proteins and inhibition of apoptosis. Thus, the present results suggested that melatonin may attenuate the inflammatory response by inhibiting the activation of the CHOP-mediated pathway in AR42J cells.

\section{Introduction}

Acute pancreatitis (SAP) is a prevalent and serious disease caused by activation of digestive proteases in the pancreas, which may result in pancreatic tissue autodigestion, tissue edema, hemorrhage or acinar necrosis, although most are mild patients (mild acute pancreatitis, MAP), $25 \%$ of patients worldwide are severe (severe acute pancreatitis, SAP), which is clinically dangerous and often complicated by systemic inflammatory response syndrome (SIRS) and multiple organ dysfunction syndrome (MODS) (1). Although gallstones are known to be the main cause of acute pancreatitis, its diagnosis and management remain challenging, and the pathogenesis of this disease is not fully understood despite the proposal of several explanatory theories (2).

The exocrine pancreas is one of the main organs responsible for digestion; thus, acinar cells have abundant endoplasmic reticulum (ER) to support their central role in the synthesis of digestive enzymes (3). Therefore, acinar cells are extremely sensitive to external stimuli in response to ER perturbations (4). A previous study reported that ER stress serves an important role during the development of AP (5). Furthermore, Hartley et al (6) identified morphological changes in the ER caused by ER stress. Pancreatic acinar cell injury, characterized by the formation of vesiculation in the ER a few minutes after a retrograde injection of taurocholate into the biliopancreatic duct in rats, has also been reported by Bhatia et al (7). Moreover, the ER is one of the largest cell organelles and is recognized as a vital site in the regulation of protein synthesis, folding and assembly, in addition to regulation of calcium ion levels and cellular stress response (8). Various external stimuli, such as calcium homeostasis imbalance, insufficient energy supply or the production of reactive oxygen species can all lead to excessive accumulation of unfolded or misfolded proteins in the ER, causing ER stress (6). To overcome ER stress, cells activate a series of specific signal transductionpathways, which are collectively 
known as the unfolded protein response (UPR) (9). The UPR in the ER is regulated by three ER membrane-associated proteins [PKR-like ER kinase (PERK), inositol-requiring enzyme 1 (IRE1) and activating transcription factor 6 (ATF6)] (10), with the initial intention to alter cellular transcriptional and translational programs, enhance protein folding ability and accelerate protein degradation, in order to restore homeostasis and normal ER function $(8,11)$. However, when ER injury is irreversible, the UPR pathways initiate apoptosis (11). Moreover, induction of the CCAAT/enhancer binding protein (C/EBP)-homologous protein (CHOP), a member of the $\mathrm{C} / \mathrm{EBP}$ family of transcription factors, is a signaling event involved in ER stress-induced apoptosis (12-14).

CHOP plays a crucial role in ER stress-induced apoptosis, and was first revealed to be one of the main mediating factors in growth arrest and damage response (15). It has been reported that $\mathrm{CHOP}$ expression is significantly increased in severe ER stress, and thus promotes cell cycle arrest and/or apoptosis $(16,17)$. However, knockdown of CHOP was revealed to confer resistance to ER stress-induced apoptosis in various experimental models (14). The involvement of CHOP-mediated apoptosis has also been revealed in numerous diseases, such as brain ischemia, diabetes, neurodegenerative abnormalities and some cardiovascular diseases $(14,18,19)$.

Previous studies have suggested that ER stress can initiate an inflammatory response via NF- $\kappa \mathrm{B}$ activation in several cells and diseases, including Alzheimer's disease and pancreatic acinar cells (20-24). Allagnat et al (25) reported that CHOP plays a pivotal role in the pathogenesis of the inflammatory response by directly contributing to $\mathrm{NF}-\kappa \mathrm{B}$ pathway activation and subsequent cytokine and chemokine expression, leading to ER stress and CHOP expression, and in turn, CHOP facilitates and amplifies NF- $\kappa \mathrm{B}$ pathway activity. Furthermore, NF- $\kappa \mathrm{B}$ is a key transcriptional factor that has an important role in the initial stage of inflammation (26), which controls the expression of numerous inflammatory mediators and cell apoptosis genes $(27,28)$. However, continued NF- $\kappa \mathrm{B}$ activity and excessive inflammatory responses lead to the development of AP $(29,30)$. Thus, it was speculated that CHOP may have a central role in the pathogenesis of inflammatory responses.

Melatonin, which is mainly secreted by the pineal gland, plays a key role in inflammation and immune defense (31). In addition, melatonin is able to attenuate oxidative stress damage and inhibit inflammatory activities (32), and has exhibited anti-inflammatory effects via the NF- $\mathrm{KB}$ signaling pathway (33). As early as 1999, studies have reported the beneficial effects of melatonin, which attenuates tissue edema and lipid peroxidation in cerulein (Cer)-induced AP (34). Moreover, previous studies revealed that melatonin can reduce liver fibrosis and cirrhosis by inhibiting ER stress $(35,36)$. However, it remains unknown whether melatonin exhibits its anti-inflammatory effect via the ER stress-induced CHOP-mediated pathway.

The present study investigated the potential role of melatonin in the CHOP-mediated signaling pathway to decrease inflammation and apoptosis in AR42J cell models of AP.

\section{Materials and methods}

Lentivirus (LV)-mediated stable RNA interference (RNAi) of $C H O P$ in AR42J cells. AR42J cells (American Type
Culture Collection) were cultured in DMEM with 20\% FBS (Sigma-Aldrich; Merck KGaA) and antibiotics (100 U/ml penicillin and $100 \mu \mathrm{l} / \mathrm{ml}$ streptomycin) at $37^{\circ} \mathrm{C}$ in a humidified incubator with $5 \% \mathrm{CO}_{2}$. The $\mathrm{LV}$ (vehicle information: hU6-MCS-Ubiquitin-EGFP-IRES-puromycin; Shanghai GeneChem Co., Ltd.), which carried short hairpin RNA (shRNA) that targeted the CHOP gene (LV-shCHOP; GenBank NM_024134) or that did not have an RNAi effect (LV-control; product no. GCNL89264) were both purchased from Shanghai GeneChem Co., Ltd., and designated as LV-shCHOP and LV-control cells, respectively.

AR42J wild-type cells (3-5x $10^{4}$ cells/well) were seeded in 12 -well plates and incubated for $24 \mathrm{~h}$ at $37^{\circ} \mathrm{C}$ in a humidified incubator with $5 \% \mathrm{CO}_{2}$. The medium in each well was subsequently replaced with $100 \mu \mathrm{l}$ viral suspension $\left(1 \times 10^{8} \mathrm{TU} / \mathrm{ml}\right)$ and $400 \mu \mathrm{l}$ DMEM without FBS and antibiotics in the presence of $10 \mu \mathrm{g} / \mathrm{ml}$ polybrene (Shanghai GeneChem Co., Ltd.). The multiplicity of infection was $\sim 100$. This was followed by $8 \mathrm{~h}$ of culture under standard conditions and then replacement with $1 \mathrm{ml}$ fresh medium. During this period, cell passaging and medium refreshment were routinely performed. After 72-96 h of virus infection, green fluorescent protein (GFP)-positive cells were observed under a Nikon inverted fluorescence microscope (Nikon Corporation) at x40 magnification. The effects of knockdown of CHOP expression in AR42J cells were analyzed by western blotting and reverse transcription-quantitative PCR (RT-qPCR).

Cell treatment and groups. In total, three types of AR42J cell lines (wild-type, LV-control and LV-shCHOP cells) were seeded in 6-well plates $\left(5 \times 10^{5}\right.$ cells/well). Following incubation for $24 \mathrm{~h}$ at $37^{\circ} \mathrm{C}$ in a humidified incubator with $5 \% \mathrm{CO}_{2}$, the groups were defined as follows: Group I, three types of AR42J cells were added to PBS alone and used as the negative control (control); Group II, three types of AR42J cells were treated with Cer (10 mM, Sigma-Aldrich; Merck KGaA) + LPS (10 mg/l, Sigma-Aldrich; Merck KGaA) to induce AP (Cer + LPS) for $8 \mathrm{~h}$ at $37^{\circ} \mathrm{C}$ in a humidified incubator with $5 \% \mathrm{CO}_{2}$; Group III, LV-control cells were treated with a low dose of melatonin (0.5 mmol/1, Sigma-Aldrich; Merck KGaA) 30 min before AP was induced $(0.5 \mathrm{mM})$ at $37^{\circ} \mathrm{C}$ in a humidified incubator with $5 \% \mathrm{CO}_{2}$; and Group IV, LV-control cells were treated with a high dose of melatonin $(2 \mathrm{mmol} / \mathrm{l}) 30 \mathrm{~min}$ before AP was induced $(2 \mathrm{mM})$ at $37^{\circ} \mathrm{C}$ in a humidified incubator with $5 \%$ $\mathrm{CO}_{2}$. Then $9 \mathrm{~h}$ later, cell extracts were collected for western blotting and RT-qPCR.

Furthermore, to assess the effects of Cer + LSP treatment on the protein expression levels of ER stress markers, apoptosis and inflammatory-related molecules, wild-type cells were treated with Cer + LPS for 0 (control), 3, 6, 9 and $12 \mathrm{~h}$ at $37^{\circ} \mathrm{C}$ in a humidified incubator with $5 \% \mathrm{CO}_{2}$, and then analyzed by western blotting. Each experiment was performed in triplicate.

Cell viability assay. The effects of melatonin on the viability of AR42J wild-type cells after Cer + LPS treatment was assessed using Cell Counting Kit-8 (CCK-8; Dojindo Molecular Technologies, Inc.) according to the manufacturer's instructions. Wild-type cells $\left(4 \times 10^{3}\right.$ cells/well) were seeded into 96-well (100 $\mu \mathrm{l} /$ well) plates. After $24 \mathrm{~h}$, the cells were treated with various concentrations of melatonin $(0.5,1,2$ and 
$4 \mathrm{mM}) 30 \mathrm{~min}$ before AP was induced (melatonin treatment groups; 0.5-4 mM), 0.01 M PBS (negative control group) and Cer + LPS (AP group) at $37^{\circ} \mathrm{C}$ in a humidified incubator with $5 \% \mathrm{CO}_{2}$. Each group consisted of five parallel wells. Following incubation for $0,3,6,9$ and $12 \mathrm{~h}$ at $37^{\circ} \mathrm{C}$ in a humidified incubator with $5 \% \mathrm{CO}_{2}, 100 \mu \mathrm{l}$ of culture medium containing $10 \mu \mathrm{l}$ CCK-8 was then added to the culture media. An enzyme standard instrument (Infinite ${ }^{\circledR} 200$ PRO NanoQuant; Tecan Austria $\mathrm{GmbH}$ ) was used to measure the supernatant of each well at a wavelength of $450 \mathrm{~nm}$. Cell viability was analyzed in each group by the optical density value. Each experiment was performed in triplicate.

Western blot analysis. Western blotting was performed to assess the protein expression levels of $\beta$-actin, $78 \mathrm{kDa}$ glucose-regulated protein (GRP78), CHOP, tumor necrosis factor- $\alpha$ (TNF- $\alpha), \mathrm{Bcl}-2, \mathrm{Bax}$, caspase-3, phospho-NF- $\kappa \mathrm{B}$ inhibitor $\alpha(\mathrm{P}-\mathrm{I} \kappa \mathrm{B} \alpha)$ and phospho-NF- $\kappa \mathrm{B}$ p65 (p-p65).

Total proteins from pancreatic acinar cells were extracted and homogenized in ice-cold RIPA buffer (Shanghai Biyuntian Bio-Technology Co., Ltd.) supplemented with protease and phosphatase inhibitors for $30 \mathrm{~min}$ on ice. The extracts were then transferred to a microcentrifuge tube and centrifuged at $1.2 \times 10^{4} \mathrm{x} \mathrm{g}$ for $20 \mathrm{~min}$ at $4^{\circ} \mathrm{C}$, and the protein concentrations were determined using a bicinchoninic acid assay kit (Thermo Fisher Scientific, Inc.). Subsequently, $45 \mu \mathrm{g}$ total protein per lane was separated by $10 \%$ SDS-PAGE and then transferred to PVDF membranes (EMD Millipore) at $300 \mathrm{~mA}$ for $0.5-1 \mathrm{~h}$. The membranes were blocked at $20-25^{\circ} \mathrm{C}$ for $2 \mathrm{~h}$ with $5 \%$ non-fat milk and then immunoblotted with specific primary antibodies overnight at $4^{\circ} \mathrm{C}$. The following primary antibodies were used: GRP78 (product code ab108615), CHOP (also known as DDIT3; product code ab179823), TNF- $\alpha$ (product code ab6671), Bcl-2 (product code ab32124), Bax (product code Ab182733) and caspase-3 (product code Ab32351; all

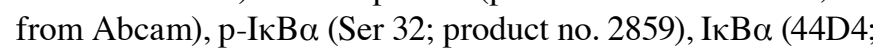
product code 4812), p-p65 (Ser 536; product code 3033), p65 (D14E12; product code 8242) and $\beta$-actin (D6A8; product code 8457) all from Cell Signaling Technology, Inc.) at 1:1,000 dilution. $\beta$-actin was used as an internal control. The following day, the membranes were washed three times with TBST containing 1\% Tween-20 for 10 min each time and incubated for $1 \mathrm{~h}$ at $20-25^{\circ} \mathrm{C}$ with a goat anti-rabbit $\mathrm{IgG}$ secondary antibody conjugated to horseradish peroxidase (1:5,000; product code BS10003; Bioworld Technology, Inc.), and then washed with TBST as before. Protein bands were visualized using a Western Bright ECL detection kit (Advansta, Inc.). Images of the protein bands were captured using the ChemiDoc MP imaging densitometer (Bio-Rad Laboratories, Inc.) and the density of the bands was quantified using Image Lab software 4.1 (Bio-Rad Laboratories, Inc.). Each experiment was performed in triplicate.

$R T-q P C R$. Total RNA from pancreatic acinar cells was extracted using TRIzol ${ }^{\circledR}$ reagent (Invitrogen; Thermo Fisher Scientific, Inc.) and then synthesized to cDNA using a RT kit (product code K1691; Invitrogen; Thermo Fisher Scientific, Inc.) at $25^{\circ} \mathrm{C}$ for $5 \mathrm{~min}, 42^{\circ} \mathrm{C}$ for $60 \mathrm{~min}$ and $70^{\circ} \mathrm{C}$ for $5 \mathrm{~min}$. PCR was subsequently performed in the presence of specific primers to the cDNA of rat genes. The PCR primers were synthesized by Sangon Biotech Co., Ltd., and the sequences were as follows: GRP78 forward, 5'-CAAGAACCAACT CACGTCCA-3' and reverse, 5'-ACCACCTTGAATGGCAAG AA-3'; CHOP forward, 5'-CCAGGAAACGAAGAGGAAG A-3' and reverse, 5'-CTTTGGGAGGTGCTTGTGA-3'; TNF- $\alpha$ forward, 5'-TGATCCGAGATGTGGAACTG-3' and reverse, 5'-CGAGCAGGAATGAGAAGAGG-3'; interleukin (IL)-6, forward 5'-TACCCCAACTTCCAATGCTC-3' and reverse, 5'-GGTTTGCCGAGTAGACCTCA-3'; Bcl-2 forward, 5'-AGG ATTGTGGCCTTCTTTGA-3' and reverse, 5'-CAGATGCCG GTTCAGGTACT-3'; Bax forward, 5'-CAGGATCGAGCA GAGAGGAT-3' and reverse, 5'-GTCCAGTTCATCGCCAAT TC-3'; caspase-3 forward, 5'-ACTGGACTGTGGCATTGA GA-3' and reverse, 5'-AATTTCGCCAGGAATAGTAACC-3'; and $\beta$-actin, forward 5'-CGTGAAAAGATGACCCAGAT-3' and reverse, 5'-ACCCTCATAGATGGGCACA-3'. The qPCR procedure was conducted using a RT qPCR system (Bio-Rad Laboratories, Inc.) with the following: Initial denaturation at $50^{\circ} \mathrm{C}$ for $2 \mathrm{~min} ; 40$ cycles of $95^{\circ} \mathrm{C}$ for $30 \mathrm{sec}, 95^{\circ} \mathrm{C}$ for $5 \mathrm{sec}$ and $60^{\circ} \mathrm{C}$ for $34 \mathrm{sec}$ ) and the Takara Power SYBR-Green PCR Master mix (cat. no. DRR820A; Takara Bio, Inc.). $\beta$-actin was used as the internal standard, and quantified relative gene expression levels were calculated using the $2^{-\Delta \Delta \mathrm{Cq}}$ method (37). Each experiment was performed in triplicate.

Statistical analysis. The results were analyzed using SPSS software 20.0 (SPSS, Inc.), and data are presented as the mean \pm SEM. One-way ANOVA followed by a Tukey's post-hoc test was performed for comparisons of $\geq 3$ groups. $\mathrm{P}<0.05$ was considered to indicate a statistically significant difference.

\section{Results}

Effects of melatonin on the viability of wild-type cells after Cer + LPS treatment. Cell viability of the Cer + LPS group was significantly reduced compared with the control group after $12 \mathrm{~h}$ of treatment (70\% viability; Fig. 1). However, when the concentration of melatonin was increased, cell viability was gradually enhanced (Fig. 1), with a maximum effect observed in the 4-mM group compared with the Cer + LPS group at the same time period (Fig. 1). Thus, it was speculated that melatonin may have a dose-dependent effect on cell viability.

Effects of Cer + LPS on the CHOP-mediated pathway at different treatment times. The expression levels of factors related to the CHOP-mediated pathway were examined by western blotting in cells cultured with Cer + LPS for 0, 3, 6,9 and $12 \mathrm{~h}$. It was demonstrated that expression levels of the inflammatory markers, p-p65, P-I $\mathrm{B} \alpha$, and TNF- $\alpha$, and ER stress markers, GRP78 and CHOP, were increased over time (Fig. 2). Moreover, the expression levels of pro-apoptosis-related molecules caspase- 3 and Bax increased, while the anti-apoptotic protein Bcl-2 decreased in the early stage of inflammation. However, at the 12-h time-point, Bax expression was decreased (Fig. 2).

Transduction efficacy of $L V$-shCHOP-mediated RNAi in AR42J cells. At 72-96 h after infection, highly efficient transduction (>95\%) of LV-shCHOP was identified in AR42J 


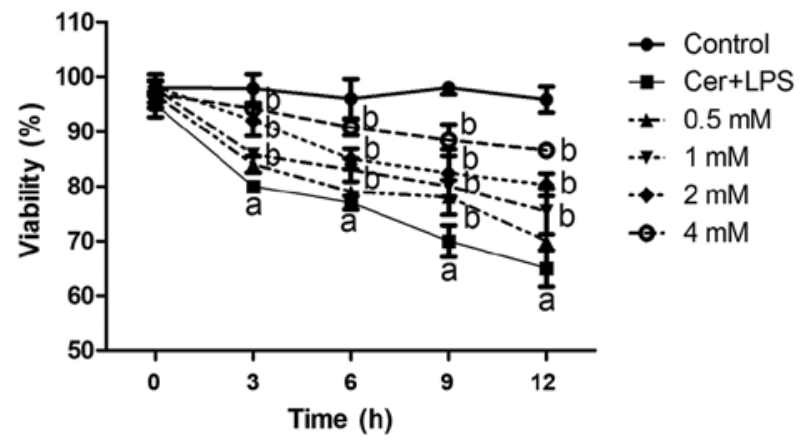

Figure 1. Effects of melatonin on the viability of AR42J cells after Cer + LPS treatment. Wild-type cells were treated with various concentrations of melatonin $(0.5,1,2$ and $4 \mathrm{mM})$ for $30 \mathrm{~min}$ before Cer + LPS treatment (melatonin treatment groups, 0.5-4 mM), 0.01 M PBS (negative control) and Cer + LPS (AP group). Cell viability was examined at $0,3,6,9$ and $12 \mathrm{~h}$ with a Cell Counting Kit- 8 assay. Data are presented as the mean \pm SEM of $\geq 3$ independent experiments. ${ }^{a} \mathrm{P}<0.05$ vs. the control group. ${ }^{b} \mathrm{P}<0.05$ vs. the Cer + LPS group at the same time period. Cer + LPS, cerulein plus LPS; AP, acute pancreatitis; LPS, lipopolysaccharide.

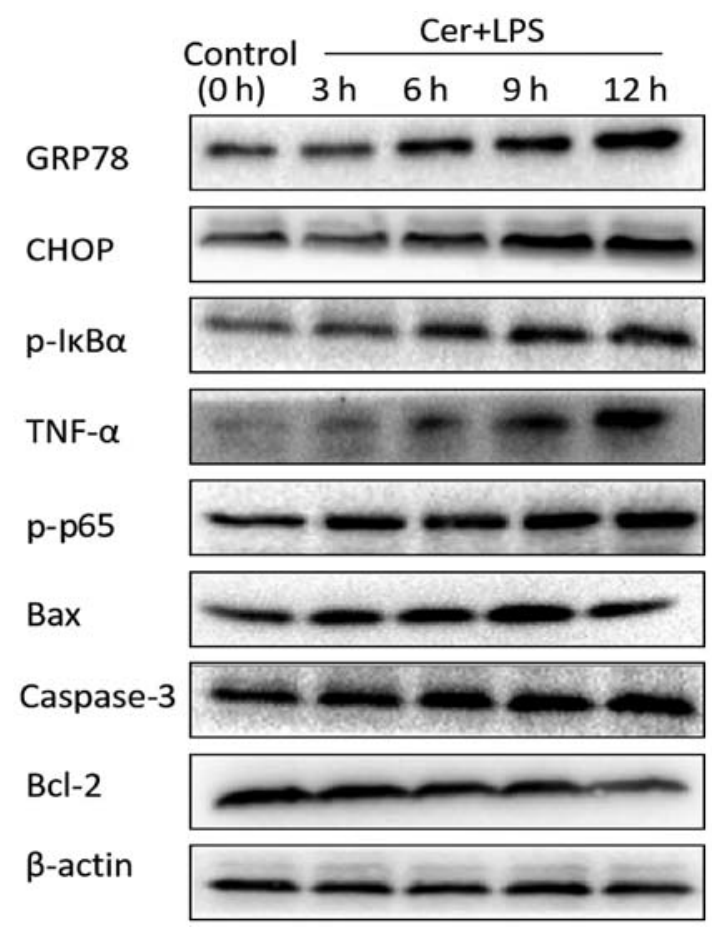

Figure 2. Effects of Cer + LPS treatment on the protein expression levels of ER stress markers, apoptosis and inflammation-related molecules in AR42J cells. Wild-type cells were treated with Cer + LPS for 0, 3, 6, 9 and $12 \mathrm{~h}$. The protein expression levels of GRP78, CHOP, p-p65, TNF- $\alpha, \mathrm{p}-\mathrm{I} \kappa \mathrm{B} \alpha, \mathrm{Bcl}-2$, Bax and caspase- 3 were assessed by western blotting, and $\beta$-actin was used as an internal control. Cer + LPS, cerulein + LPS; LPS, lipopolysaccharide; GRP78, 78 kDa glucose-regulated protein; CHOP, CCAAT/enhancer binding protein $(\mathrm{C} / \mathrm{EBP})$-homologous protein; $\mathrm{p}-\mathrm{I} \kappa \mathrm{B} \alpha$, phospho-NF- $\kappa \mathrm{B}$ inhibitor $\alpha$; TNF- $\alpha$, tumor necrosis factor- $\alpha$; p-p65, phospho-NF- $\kappa$ B p65.

cells, as GFP expression was observed under a Nikon inverted fluorescence microscope (Fig. 3), and the LV-control and LV-shCHOP cells had similar transduction efficiencies (Fig. 3).

Effects of Cer + LPS and treatment with melatonin on the expression of ER stress-related factors. Western blotting results identified increased GRP78 and CHOP protein expression levels in LV-control cells treated with Cer + LPS compared with the respective controls, and there were no differences between wild-type cells and LV-control cells. However, LV-shCHOP cells after Cer + LPS treatment and LV-control cells in the melatonin treatment groups both had reduced GRP78 and CHOP expression levels, compared with LV-control cells treated with Cer + LPS (Fig. 4A). These findings were also demonstrated by RT-qPCR (Fig. 4B). LV-shCHOP cells had a greater effect of silencing on CHOP expression in AR42J cells and significantly attenuated ER stress after Cer + LPS treatment. Moreover, pre-treatment of LV-control cells with melatonin also downregulated CHOP expression and inhibited ER stress to protect the cells. Therefore, the extent of inhibition by melatonin was dose dependent.

Effects of Cer + LPS and treatment with melatonin on inflammation and apoptosis-associated molecules. The expression levels of NF- $\kappa \mathrm{B}$ pathway and pro-inflammatory molecules were increased following Cer + LPS treatment, compared with the respective controls. However, the expression levels of these molecules in LV-shCHOP cells after Cer + LPS treatment and LV-control cells in the melatonin treatment groups were lower compared with the LV-control cells, after Cer + LPS treatment (Fig. 5A and B).

Furthermore, there were significantly enhanced Bax and caspase-3 expression levels and reduced Bcl-2 expression in LV-control cells after Cer + LPS treatment, compared with the respective controls (Fig. 6A and B). Moreover, LV-shCHOP cells treated with Cer + LPS and LV-control cells in the melatonin treatment groups had significantly reduced expression levels of Bax and caspase- 3 and enhanced expression of Bcl-2 compared with the LV-control cells treated with Cer + LPS. Collectively, the results indicated that knockdown of CHOP expression reduced activation of the $N F-\kappa B$ pathway, inflammation and the apoptotic response after Cer + LPS treatment, while pre-treatment with melatonin also attenuated inflammation and apoptosis. Furthermore, the extent of inhibition by melatonin exhibited a dose-dependent effect.

\section{Discussion}

The present results indicated that melatonin had an anti-inflammatory effect via the ER stress-induced CHOP-mediated pathway in AR42J cells. Moreover, ER stress was significantly activated in the early stage of AP induced by Cer + LPS. The CHOP-mediated pathway also aggravated acinar cell damage by inducing apoptosis and $\mathrm{NF}-\kappa \mathrm{B}$ activation. Furthermore, it was indicated that treatment with melatonin significantly attenuated the expression of pro-inflammatory cytokines and ER stress-related molecules, and exerted a protective effect by inhibiting apoptosis of acinar cells.

In cells, heat shock proteins (HSPs) promote the modification of newly synthesized proteins in the ER and their translocation to the cellular membrane (38), and this is essential in the process of recovery to reduce stimulation and injury (39). In addition, under inflammatory conditions, the regulation of HSPs may attenuate the inflammatory response (40). GRP78, which belongs to the HSP family, is important in the response to ER stress (41). When excess unfolded or misfolded proteins 


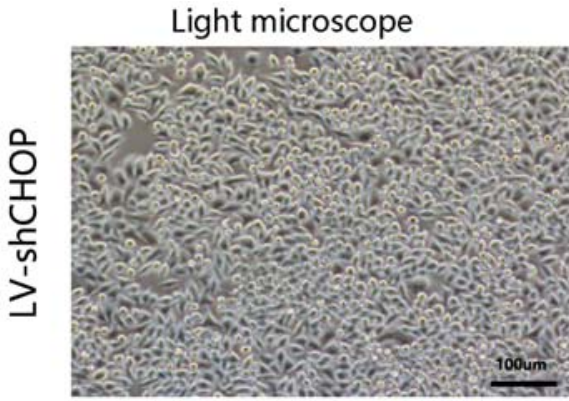

Light microscope

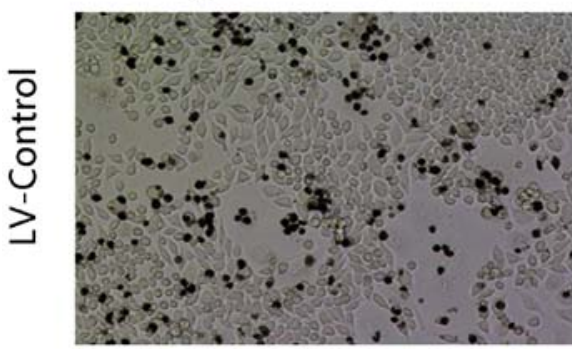

Fluorescent microscope

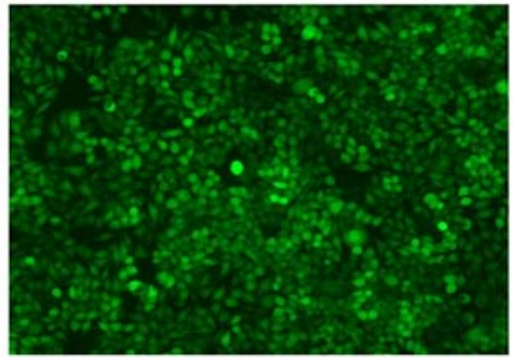

Fluorescent microscope

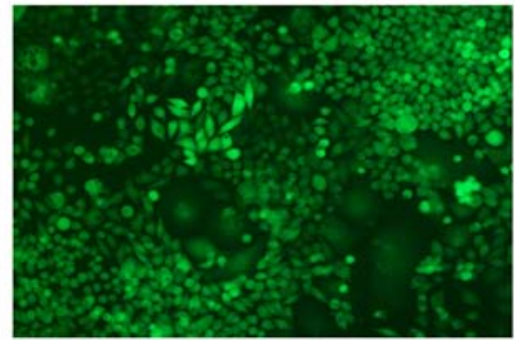

Figure 3. Infection efficacy of LV-shCHOP and LV-control mediated RNA interference in AR42J cells. The transduction efficiencies of these two types of cells were detected using light microscopy and fluorescent microscopy. Magnification, $\mathrm{x} 40$. Scale bar, $100 \mu \mathrm{m}$. LV, lentivirus; sh, short hairpin RNA; CHOP, CCAAT/enhancer binding protein (C/EBP)-homologous protein.

A
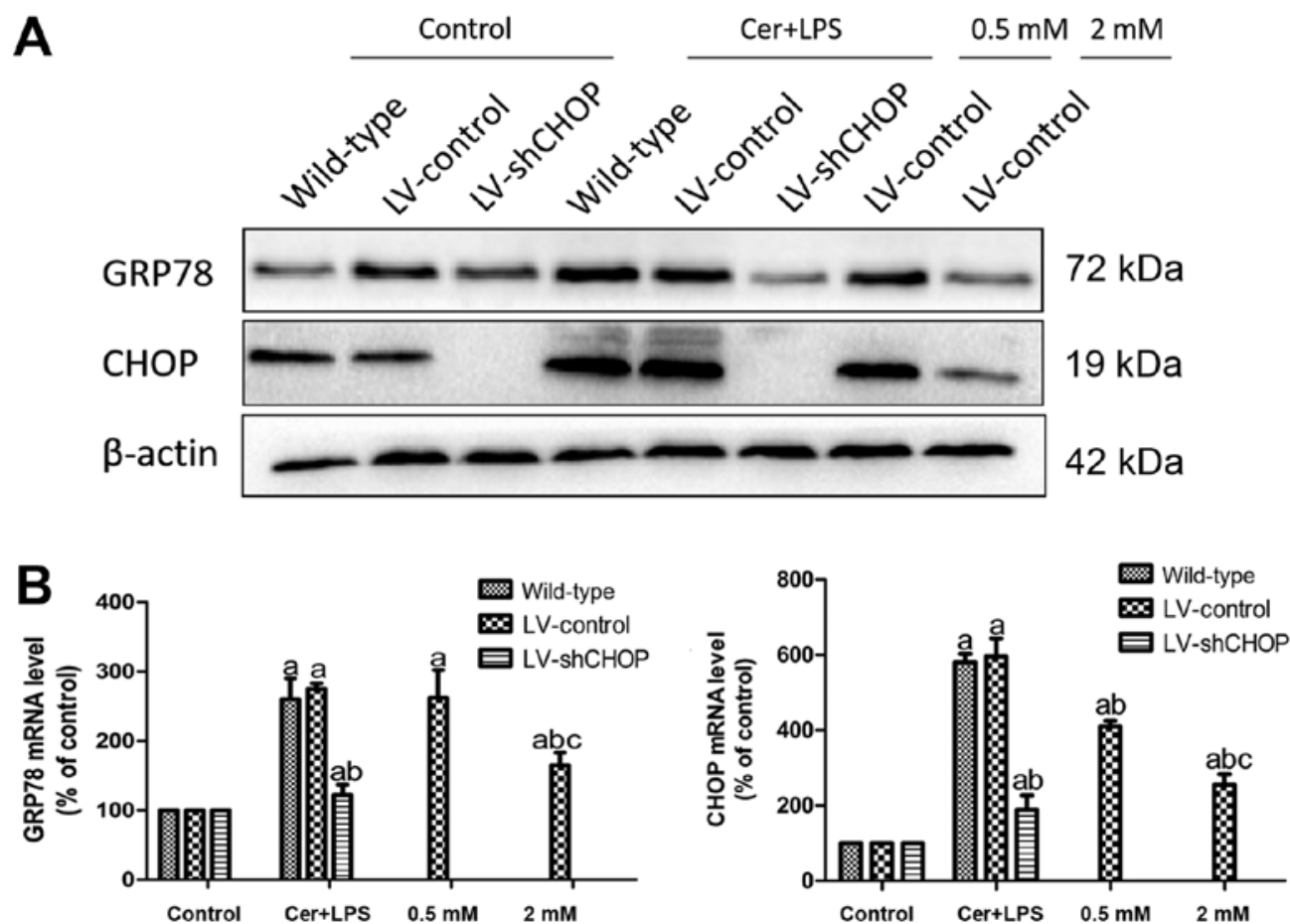

Figure 4. Effects of Cer + LPS and treatment with melatonin on the expression of ER stress-related molecules in AR42J cells. (A) Protein expression levels of GRP78 and CHOP at $9 \mathrm{~h}$ after Cer + LPS and melatonin treatment were assessed by western blotting, and $\beta$-actin was used as the internal control. (B) mRNA expression levels of GRP78 and CHOP were quantified by reverse transcription-quantitative PCR at $9 \mathrm{~h}$. Data are presented as the mean \pm SEM of $\geq 3$ independent experiments. Control, treated with PBS; $0.5 \mathrm{mM}$, treated with $0.5 \mathrm{mM}$ melatonin 30 min before CER + LPS treatment; $2 \mathrm{mM}$, treated with $2 \mathrm{mM}$ melatonin 30 min before CER + LPS treatment. ${ }^{a} \mathrm{P}<0.05$ vs. the respective controls. ${ }^{b} \mathrm{P}<0.05$ vs. the LV-control cells treated with Cer $+\mathrm{LPS}$. ${ }^{\mathrm{c}} \mathrm{P}<0.05$ vs. the $0.5 \mathrm{mM}$ group. Cer + LPS, cerulein + LPS; LV, lentivirus; sh, short hairpin RNA; CHOP, CCAAT/enhancer binding protein (C/EBP)-homologous protein; LPS, lipopolysaccharide; GRP78, 78 kDa glucose-regulated protein.

accumulate in the ER causing ER stress, GRP78 separates from the three major triggering molecules (ATF6, PERK and IRE1) of the UPR, thus initiating the downstream UPR signaling pathways (42). The present results revealed that
GRP78 was upregulated early after Cer + LPS treatment and exhibited a time-dependent increase, which suggested that ER stress was activated early in AP and became increasingly severe over time. 

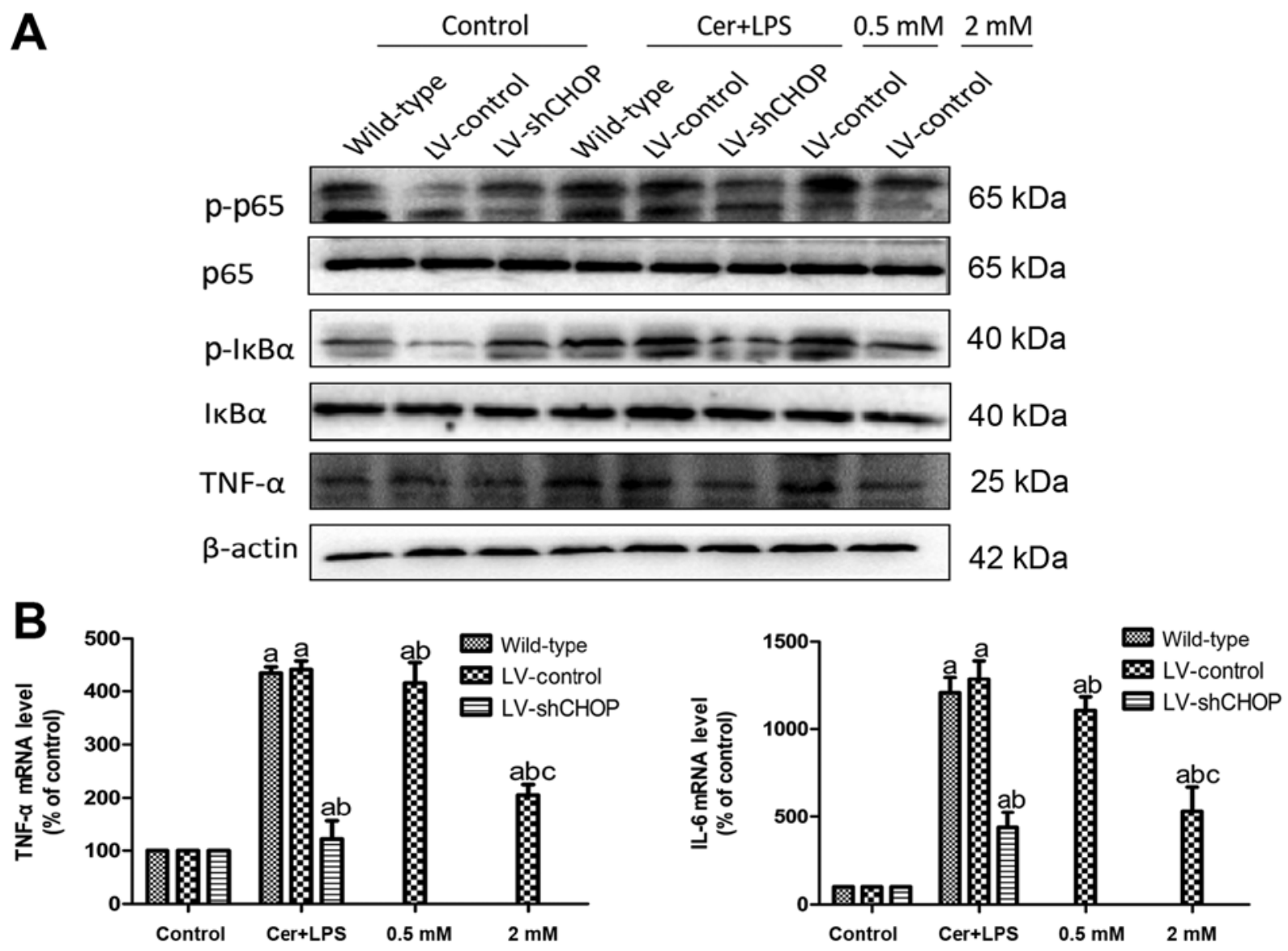

Figure 5. Effects of Cer + LPS and treatment with melatonin on the expression of inflammation-related molecules in AR42J cells. (A) Protein expression levels of p-p65, p65, p-IкB $\alpha, \mathrm{I \kappa B} \alpha$ and TNF- $\alpha$ at $9 \mathrm{~h}$ after Cer + LPS and melatonin treatment were assessed by western blotting, and $\beta$-actin was used as the internal control. (B) mRNA expression levels of IL- 6 and TNF- $\alpha$ were quantified by reverse transcription-quantitative PCR at $9 \mathrm{~h}$. Data are presented as the mean \pm SEM of $\geq 3$ independent experiments. Control, treated with PBS; $0.5 \mathrm{mM}$, treated with $0.5 \mathrm{mM}$ melatonin 30 min before Cer + LPS treatment; $2 \mathrm{mM}$, treated with $2 \mathrm{mM}$ melatonin $30 \mathrm{~min}$ before Cer + LPS treatment. ${ }^{a} \mathrm{P}<0.05$ vs. the respective controls. ${ }^{b} \mathrm{P}<0.05$ vs. the LV-control cells treated with Cer + LPS. ${ }^{c} \mathrm{P}<0.05$ vs. the $0.5 \mathrm{mM}$ group. Cer + LPS, cerulein + LPS; LV, lentivirus; sh, short hairpin RNA; CHOP, CCAAT/enhancer binding protein

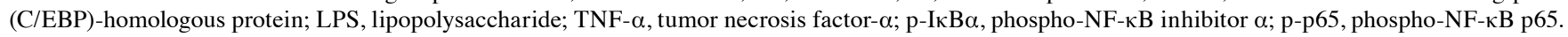

Apoptosis is the process of programmed cell death. Numerous studies have reported that apoptosis and necrosis occur in clinical and experimental AP (43-45), and some studies have indicated that these are involved in ER stress-induced apoptosis $(46,47)$. Furthermore, the apoptotic signal can be induced when cells are subjected to excessive and prolonged ER stress (11).

Previous studies have revealed that ER stress can exacerbate inflammatory damage in pancreatic tissue by regulating cell death, and thus promote the development of pancreatitis (48-50). ER stress-induced apoptosis includes the following three signaling pathways: i) CHOP-mediated apoptosis via the downregulation of Bcl-2; ii) caspase-12-mediated pathway, which plays a role in apoptosis by activating caspase- 9 and caspase-3; and iii) kinase 1-c-Jun N-terminal kinase pathway activation $(13,14)$. Therefore, it is important to identify the extent to which signaling pathways contribute to acinar cell apoptosis after Cer + LPS treatment. CHOP is a pro-apoptotic molecule and can be activated by all three branches of the ER stress pathway, and in turn has been targeted for the modulation of ER stress (51). In the present study, the in vitro models of AP demonstrated that CHOP expression was significantly increased after Cer + LPS treatment, indicating that ER stress was activated early in AR42J cells under the condition of Cer + LPS-induced inflammation. Thus, the LV-mediated RNAi method was used to determine the potential role of CHOP in the regulation of cell apoptosis during AP. The present results indicated that the mRNA and protein expression levels of CHOP could be specifically silenced, while this did not occur using a non-target LV that did not have an RNAi effect on CHOP expression in AR42J cells. Furthermore, knockdown of CHOP led to an almost complete suppression of apoptosis after Cer + LPS treatment, which significantly decreased the expression levels of Bax and caspase-3, and increased the expression of Bcl-2 in the experimental pancreatitis model. This pro-apoptotic potential may be due to CHOP, as it is one of the highest inducible genes underlying ER stress. Moreover, excessively activated IRE1 $\alpha$ may result from the recruitment of TNF receptor-associated factor 2 (TRAF2) and its combining with apoptosis signal-regulated kinase 1 (ASK1) to form the IRE-1-TRAF2-ASK1 complex on the outer membrane of ER, which activates the c-Jun amino-terminal kinase and p38 mitogen-activated protein kinase (52). In addition, phosphorylation of p38 mitogen-activated protein kinase can induce the expression of CHOP after transduction of the activation domain serine 78/81 $(14,52,53)$. ER stress-induced 

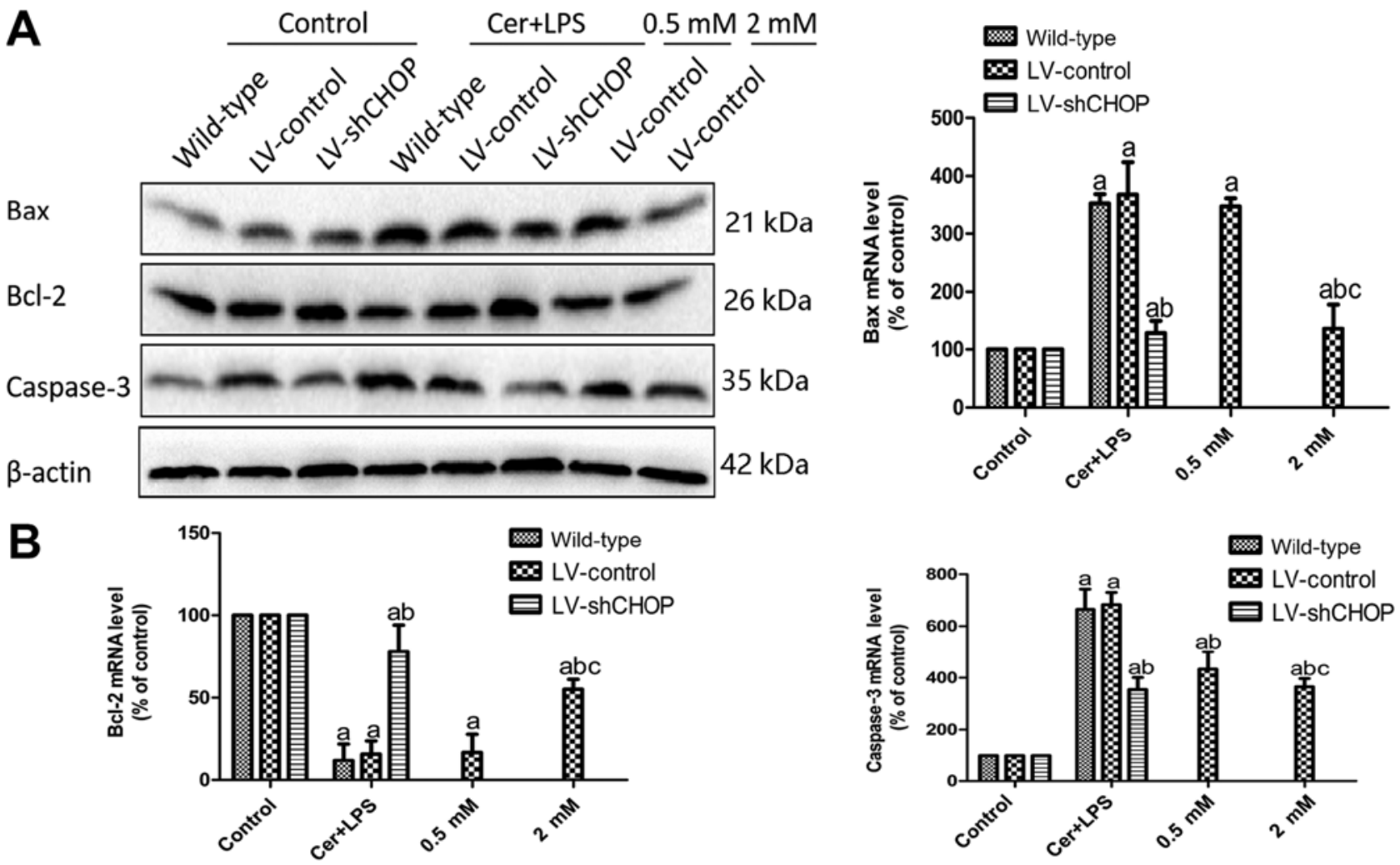

Figure 6. Effects of Cer + LPS and treatment with melatonin on the expression of apoptosis-related molecules in AR42J cells. (A) Protein expression levels of Bax, Bcl-2 and caspase- 3 at $9 \mathrm{~h}$ after Cer + LPS and melatonin treatment were assessed by western blotting, and $\beta$-actin was used as the internal control. (B) mRNA expression levels of Bcl-2, Bax and caspase-3 were quantified by reverse transcription-quantitative PCR at $9 \mathrm{~h}$. Data are presented as the mean \pm SEM of $\geq 3$ independent experiments. Control, treated with PBS; $0.5 \mathrm{mM}$, treated with $0.5 \mathrm{mM}$ melatonin 30 min before cerulein + LPS treatment; $2 \mathrm{mM}$, treated with $2 \mathrm{mM}$ melatonin 30 min before cerulein + LPS treatment. ${ }^{\mathrm{a}} \mathrm{P}<0.05$ vs. the respective controls. ${ }^{b} \mathrm{P}<0.05$ vs. the $\mathrm{LV}$-control cells treated with Cer + LPS. ${ }^{~} \mathrm{P}<0.05$ vs. the $0.5 \mathrm{mM}$ group. Cer + LPS, cerulein + LPS; LV, lentivirus; sh, short hairpin RNA; CHOP, CCAAT/enhancer binding protein (C/EBP)-homologous protein; LPS, lipopolysaccharide.

CHOP-mediated apoptosis is speculated to upregulate the pro-apoptotic molecule Bax and translocation of Bax to the mitochondria, downregulate anti-apoptotic molecules such as Bcl-2 and Bcl-xl (14,54,55), and activate growth arrest and DNA damage inducible 34 and ER oxidoreductin-1a (51). Collectively, these findings indicated that CHOP plays a central role in pancreatitis acinar cell apoptosis and leads to acinar cell injury in AP. Therefore, in the future, CHOP inhibitors may be developed as novel therapeutic drugs for AP.

In recent years, the ER stress-induced, CHOP-mediated pathway has been reported in various inflammatory diseases $(8,56-58)$, but to the best of our knowledge, it has not been demonstrated in a cell model of pancreatic injury. The present results revealed that the CHOP-mediated pathway enhances pancreatitis inflammation, possibly via the transcriptional regulation of NF- $\mathrm{KB}$, and this was consistent with the findings from Allagnat et al (25). NF- $\mathrm{KB}$ plays an important role in the inflammatory response (29). When cells are subjected to pathological stimulation such as inflammation or

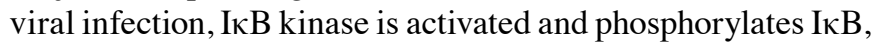
which is subsequently degraded and exposes a nuclear-localization signal for NF- $\mathrm{kB}$, allowing NF- $\mathrm{kB}$ to rapidly migrate into the nucleus, where it initiates the transcription and activation of numerous inflammation-associated genes (12). In addition, the association between ER stress and the inflammatory response are interconnected, and inflammation can regulate and activate ER stress in cells (12). Zhang et al (59) revealed that ER stress can activate the cAMP-responsive element-binding protein $\mathrm{H}$ (CREBH) to induce an acute inflammatory response, and pro-inflammatory cytokines such as IL-6, IL- $1 \beta$ or TNF- $\alpha$ can also exacerbate ER stress and promote the production of CREBH in hepatoma cells in vivo. Previous studies have also reported that inflammatory factors can lead to insulin resistance, promote the occurrence and development of metabolic syndrome, and aggravate tissue and cell stress and damage $(60,61)$. In line with these previous findings, the present results demonstrated that the NF- $\mathrm{BB}$ pathway and pro-inflammatory cytokines were significantly reduced by CHOP knockdown after Cer + LPS treatment. Therefore, it was speculated that CHOP knockdown inhibited NF- $\kappa \mathrm{B}$ signaling pathway activation and attenuated pancreatitis inflammation and acinar cell injury. Thus, the present results suggested that ER stress-induced, CHOP-mediated pathway had a detrimental role in the pathogenesis of AP.

Other pro-inflammatory mechanisms of CHOP have also been investigated in previous studies. For example, one study using a CHOP-deficient mouse model of experimental pancreatitis identified a reduction in pancreatic tissue inflammation and IL-1 $\beta$ activity by inhibiting the induction of inflammation-associated caspases, caspase-11 and caspase-1 (56). It has also been revealed that in a mouse model of myocardial ischemia/reperfusion injury, knockdown of 
CHOP led to reduced myocardial inflammation, possibly via the regulation of the transcription of specific pro-inflammatory cytokine genes, such as IL-6 (8). However, the underlying molecular mechanisms of the CHOP-mediated pathway and pro-inflammatory activity are not fully understood and require further investigation.

The anti-inflammatory effects of melatonin on pancreatitis have been reported in numerous cellular and animal studies, which also functions as a protectant and antioxidant; however, the potential mechanisms are largely unknown (32). It has also been revealed that melatonin could reduce cell injury in different models via the inhibition of ER stress (58). Moreover, the present results revealed that treatment with melatonin significantly decreased the protein expression of $\mathrm{CHOP}$, inhibited the activation of the $\mathrm{NF}-\kappa \mathrm{B}$ signaling pathway and the release of pro-inflammatory factors, as well as attenuated the ER stress and suppressed apoptosis of AR42J cells. Thus, it was speculated that melatonin protected acinar cells against AP, and alleviated acinar cell injury and inflammatory response by inhibiting the ER stress-induced, CHOP-mediated pathway.

However, the present study had some limitations. The clinical application of melatonin is still not universal, and further clinical trials are required. Moreover, the underlying anti-inflammatory molecular mechanism and the optimal concentration of melatonin need to be identified, in order to further reduce pancreatitis mortality and improve survival prognosis.

\section{Acknowledgements}

Not applicable.

\section{Funding}

This study was supported by the Public Projects of Zhejiang Province (grant no. 2016C33215).

\section{Availability of data and materials}

The datasets used and/or analyzed during the current study are available from the corresponding author on reasonable request.

\section{Authors' contributions}

QZ and HZ performed the majority of the research. JH and XL designed the study. XJ and JW analyzed the data. XL, JW and HZ collected the information. QZ wrote the manuscript. All authors read and approved the final manuscript.

\section{Ethics approval and consent to participate}

Not applicable.

\section{Patient consent for publication}

Not applicable.

\section{Competing interests}

The authors declare that they have no competing interests.

\section{References}

1. Bhatia M, Wong FL, Cao Y, Lau HY, Huang J, Puneet P and Chevali L: Pathophysiology of acute pancreatitis. Pancreatology 5: 132-144, 2005.

2. Walczak-Galezewska MK, Skrypnik D, Szulinska M, Skrypnik K and Bogdanski P: Conservative management of acute calculous cholecystitis complicated by pancreatitis in an elderly woman: A case report. Medicine (Baltimore) 97: e11200, 2018.

3. Berridge MJ: The endoplasmic reticulum: A multifunctional signaling organelle. Cell Calcium 32: 235-249, 2002.

4. Kubisch CH and Logsdon CD: Endoplasmic reticulum stress and the pancreatic acinar cell. Expert Rev Gastroenterol Hepatol 2: 249-260, 2008

5. Thrower EC, Gorelick FS and Husain SZ: Molecular and cellular mechanisms of pancreatic injury. Curr Opin Gastroenterol 26: 484-489, 2010.

6. Hartley T, Siva M, Lai E, Teodoro T, Zhang L and Volchuk A: Endoplasmic reticulum stress response in an INS-1 pancreatic beta-cell line with inducible expression of a folding-deficient proinsulin. BMC Cell Biol 11: 59, 2010.

7. Bhatia M, Neoptolemos JP and Slavin J: Inflammatory mediators as therapeutic targets in acute pancreatitis. Curr Opin Investig Drugs 2: 496-501, 2001.

8. Miyazaki Y, Kaikita K, Endo M, Horio E, Miura M, Tsujita K, Hokimoto S, Yamamuro M, Iwawaki T, Gotoh T, et al: C/EBP homologous protein deficiency attenuates myocardial reperfusion injury by inhibiting myocardial apoptosis and inflammation. Arterioscler Thromb Vasc Biol 31: 1124-1132, 2011.

9. Guo G, Meng Y, Tan W, Xia Y, Cheng C, Chen X and Gu Z: Induction of apoptosis coupled to endoplasmic reticulum stress through regulation of CHOP and JNK in bone marrow mesenchymal stem cells from patients with systemic lupus erythematosus. J Immunol Res 2015: 183738, 2015.

10. Boyce $\mathrm{M}$ and Yuan J: Cellular response to endoplasmic reticulum stress: A matter of life or death. Cell Death Differ 13: 363-373, 2006.

11. Wu JS, Li WM, Chen YN, Zhao Q and Chen QF: Endoplasmic reticulum stress is activated in acute pancreatitis. J Dig Dis 17: 295-303, 2016.

12. Zhang K and Kaufman RJ: From endoplasmic-reticulum stress to the inflammatory response. Nature 454: 455-462, 2008.

13. Xu C, Bailly-Maitre B and Reed JC: Endoplasmic reticulum stress: Cell life and death decisions. J Clin Invest 115: 2656-2664, 2005.

14. Oyadomari S and Mori M: Roles of CHOP/GADD153 in endoplasmic reticulum stress. Cell Death Differ 11: 381-389, 2004.

15. Park JS, Luethy JD, Wang MG, Fargnoli J, Fornace AJ Jr, McBride OW and Holbrook NJ: Isolation, characterization and chromosomal localization of the human GADD153 gene. Gene 116: 259-267, 1992.

16. Wang XZ, Lawson B, Brewer JW, Zinszner H, Sanjay A, Mi LJ, Boorstein R, Kreibich G, Hendershot LM and Ron D: Signals from the stressed endoplasmic reticulum induce C/EBP-homologous protein (CHOP/GADD153). Mol Cell Biol 16: 4273-4280, 1996.

17. Matsumoto M, Minami M, Takeda K, Sakao Y and Akira S: Ectopic expression of CHOP (GADD153) induces apoptosis in M1 myeloblastic leukemia cells. FEBS Lett 395: 143-147, 1996.

18. Myoishi M, Hao H, Minamino T, Watanabe K, Nishihira K, Hatakeyama K, Asada Y, Okada K, Ishibashi-Ueda H, Gabbiani G, et al: Increased endoplasmic reticulum stress in atherosclerotic plaques associated with acute coronary syndrome. Circulation 116: 1226-1233, 2007.

19. Fu HY, Okada K, Liao Y, Tsukamoto O, Isomura T, Asai M, Sawada T, Okuda K, Asano Y, Sanada S, et al: Ablation of C/EBP homologous protein attenuates endoplasmic reticulum-mediated apoptosis and cardiac dysfunction induced by pressure overload. Circulation 122: 361-369, 2010.

20. Walter P and Ron D: The unfolded protein response: From stress pathway to homeostatic regulation. Science 334: 1081-1086, 2011.

21. Kitamura M: Control of NF-kB and inflammation by the unfolded protein response. Int Rev Immunol 30: 4-15, 2011.

22. Kitamura M: Biphasic, bidirectional regulation of NF-kappaB by endoplasmic reticulum stress. Antioxid Redox Signal 11: 2353-2364, 2009.

23. Sah RP, Dudeja V, Dawra RK and Saluja AK: Cerulein-induced chronic pancreatitis does not require intra-acinar activation of trypsinogen in mice. Gastroenterology 144: 1076-1085.e1072, 2013. 
24. Sah RP, Garg SK, Dixit AK, Dudeja V, Dawra RK and Saluja AK: Endoplasmic reticulum stress is chronically activated in chronic pancreatitis. J Biol Chem 289: 27551-27561, 2014.

25. Allagnat F, Fukaya M, Nogueira T, Delaroche D, Welsh N, Marselli L, Marchetti P, Haefliger JA, Eizirik DL and Cardozo AK: C/EBP homologous protein contributes to cytokine-induced pro-inflammatory responses and apoptosis in ß-cells. Cell Death Differ 19: 1836-1846, 2012.

26. Rius J, Guma M, Schachtrup C, Akassoglou K, Zinkernagel AS Nizet V, Johnson RS, Haddad GG and Karin M: NF-kappaB links innate immunity to the hypoxic response through transcriptional regulation of HIF-1alpha. Nature 453: 807-811, 2008.

27. Sun XF and Zhang $\mathrm{H}$ : NF- $\kappa \mathrm{B}$ and $\mathrm{NF}-\kappa \mathrm{B} 1$ polymorphisms in relation to susceptibility of tumor and other diseases. Histo Histopatol 22: 1387-1398, 2007.

28. Czyz M: Specificity and selectivity of the NFkappaB response Postepy Biochem 51: 60-68, 2005 (In Polish).

29. Huang H, Liu Y, Daniluk J, Gaiser S, Chu J, Wang H, Li ZS, Logsdon CD and Ji B: Activation of nuclear factor-kB in acinar cells increases the severity of pancreatitis in mice. Gastroenterology 144: 202-210, 2013.

30. Sah RP, Garg P and Saluja AK: Pathogenic mechanisms of acute pancreatitis. Curr Opin Gastroenterol 28: 507-515, 2012.

31. Wang H, Li L, Zhao M, Chen YH, Zhang ZH, Zhang C, Ji YL, Meng XH and Xu DX: Melatonin alleviates lipopolysaccharide-induced placental cellular stress response in mice. J Pineal Res 50: 418-426, 2011.

32. Jaworek J, Leja-Szpak A, Kot M, Jaworek A, Nawrot-Porbka K, Bonior $\mathbf{J}$ and Szklarczyk J: The role of melatonin in pancreatic protection: Could melatonin be used in the treatment of acute pancreatitis? Curr Pharm Des 20: 4834-4840, 2014.

33. Forman K, Vara E, Garcia C, Kireev R, Cuesta S, Acuña-Castroviejo D and Tresguerres JA: Beneficial effects of melatonin on cardiological alterations in a murine model of accelerated aging. J Pineal Res 49: 312-320, 2010.

34. Qi W, Tan DX, Reiter RJ, Kim SJ, Manchester LC, Cabrera J, Sainz RM and Mayo JC: Melatonin reduces lipid peroxidation and tissue edema in cerulein-induced acute pancreatitis in rats. Dig Dis Sci 44: 2257-2262, 1999.

35. Kim SJ, Kang HS, Lee JH, Park JH, Jung CH, Bae JH, Oh BC, Song DK, Baek WK and Im SS: Melatonin ameliorates ER stress-mediated hepatic steatosis through miR-23a in the liver. Biochem Biophys Res Commun 458: 462-469, 2015.

36. San-Miguel B, Crespo I, Sanchez DI, González-Fernández B, Ortiz de Urbina JJ, Tuñón MJ and González-Gallego J: Melatonin inhibits autophagy and endoplasmic reticulum stress in mice with carbon tetrachloride-induced fibrosis. J Pineal Res 59: 151-162, 2015.

37. Livak KJ and Schmittgen TD: Analysis of relative gene expression data using real-time quantitative PCR and the 2(-Delta Delta C(T)) method. Methods 25: 402-408, 2001.

38. Hartl FU and Hayer-Hartl M: Molecular chaperones in the cytosol: From nascent chain to folded protein. Science 295 $1852-1858,2002$

39. Pfaffenbach KT and Lee AS: The critical role of GRP78 in physiologic and pathologic stress. Curr Opin Cell Biol 23: 150-156, 2011.

40. Ni M and Lee AS: ER chaperones in mammalian development and human diseases. FEBS Lett 581: 3641-3651, 2007.

41. Lee AS: The glucose regulated proteins: Stress induction and clinical applications. Trends Biochem Sci 26: 504-510, 2001.

42. Kimata $Y$ and Kohno K: Endoplasmic reticulum stress-sensing mechanisms in yeast and mammalian cells. Curr Opin Cell Biol 23: 135-142, 2011.

43. Gukovskaya AS and Pandol SJ: Cell death pathways in pancreatitis and pancreatic cancer. Pancreatology 4: 567-586, 2004.

44. Bhatia M: Apoptosis versus necrosis in acute pancreatitis. Am J Physiol Gastrointest Liver Physiol 286: 189-196, 2004.
45. Mareninova OA, Sung KF, Hong P, Lugea A, Pandol SJ, Gukovsky I and Gukovskaya AS: Cell death in pancreatitis: Caspases protect from necrotizing pancreatitis. J Biol Chem 281: 3370-3381, 2006

46. Liu Y, Yang L, Chen KL, Zhou B, Yan H, Zhou ZG and Li Y Knockdown of GRP78 promotes apoptosis in pancreatic acinar cells and attenuates the severity of cerulein and LPS induced pancreatic inflammation. PLoS One 9: e92389, 2014.

47. Williams JA, Sans MD, Tashiro M, Schäfer C, Bragado MJ and Dabrowski A: Cholecystokinin activates a variety of intracellular signal transduction mechanisms in rodent pancreatic acinar cells. Pharmacol Toxicol 91: 297-303, 2002.

48. Wu L, Cai B, Zheng S, Liu X, Cai H and Li H: Effect of emodin on endoplasmic reticulum stress in rats with severe acute pancreatitis. Inflammation 36: 1020-1029, 2013.

49. Jacob TG, Sreekumar VI, Roy TS and Garg PK: Electron-microscopic evidence of mitochondriae containing macroautophagy in experimental acute pancreatitis: Implications for cell death. Pancreatology 14: 454-458, 2014.

50. Hall JC and Crawford HC: The conspiracy of autophagy, stress and inflammation in acute pancreatitis. Curr Opin Gastroenterol 30: 495-499, 2014.

51. Nashine S, Liu Y, Kim BJ, Clark AF and Pang IH: Role of C/EBP homologous protein in retinal ganglion cell death after ischemia/reperfusion injury. Invest Ophthalmol Vis Sci 56: 221-231, 2014.

52. Nishitoh H, Matsuzawa A, Tobiume K, Saegusa K, Takeda K, Inoue $\mathrm{K}$, Hori S, Kakizuka A and Ichijo H: ASK1 is essential for endoplasmic reticulum stress-induced neuronal cell death triggered by expanded polyglutamine repeats. Genes Dev 16: $1345-1355,2002$

53. Nagai H, Noguchi T, Takeda $K$ and Ichijo $H$ : Pathophysiological roles of ASK1-MAP kinase signaling pathways. J Biochem Mol Biol 40: 1-6, 2007.

54. McCullough KD, Martindale JL, Klotz LO, Aw TY and Holbrook NJ: Gadd153 sensitizes cells to endoplasmic reticulum stress by down-regulating $\mathrm{Bcl} 2$ and perturbing the cellular redox state. Mol Cell Boil 21: 1249-1259, 2001.

55. Gotoh T, Terada K, Oyadomari S and Mori M: hsp70-DnaJ chaperone pair prevents nitric oxide- and CHOP-induced apoptosis by inhibiting translocation of Bax to mitochondria. Cell Death Differ 11: 390-402, 2004

56. Suyama K, Ohmuraya M, Hirota M, Ozaki N, Ida S, Endo M, Araki K, Gotoh T, Baba H and Yamamura K: C/EBP homologous protein is crucial for the acceleration of experimental pancreatitis. Biochem Biophys Res Commun 367: 176-182, 2008.

57. Endo M, Mori M, Akira S and Gotoh T: C/EBP homologous protein (CHOP) is crucial for the induction of caspase-11 and the pathogenesis of lipopolysaccharide-induced inflammation. J Immunol 176: 6245-6253, 2006.

58. Namba T, Tanaka K, Ito Y, Ishihara T, Hoshino T, Gotoh T, Endo $\mathrm{M}$, Sato $\mathrm{K}$ and Mizushima T: Positive role of CCAAT/enhancer-binding protein homologous protein, a transcription factor involved in the endoplasmic reticulum stress response in the development of colitis. Am J Pathol 174: 1786-1798, 2009

59. Zhang K, Shen X, Wu J, Sakaki K, Saunders T, Rutkowski DT, Back SH and Kaufman RJ: Endoplasmic reticulum stress activates cleavage of CREBH to induce a systemic inflammatory response. Cell 124: 587-599, 2006.

60. Matulewicz $\mathrm{N}$ and Karczewska-Kupczewska $\mathrm{M}$ : Insulin resistance and chronic inflammation. Postepy Hig Med Dosw (Online) 70: 1245-1258, 2016

61. Musialik K, Szulinska M, Hen K, Skrypnik D and Bogdanski P: The relation between osteoprotegerin, inflammatory processes, and atherosclerosis in patients with metabolic syndrome. Eur Rev Med Pharmacol Sci 21: 4379-4385, 2017. 